\title{
Diferentes formas de ver o dinheiro: a ótica dos jovens que vêm estudar em Santa Maria
}

\author{
Cláudia Lunardi ${ }^{1}$ \\ Luis Felipe Dias Lopes ${ }^{2}$ \\ Juciéle Fátima Coradini ${ }^{3}$ \\ Jonathan Saidelles Corrêa ${ }^{4}$ \\ Damiana Machado de Almeida ${ }^{5}$
}

\begin{abstract}
Resumo: A conversibilidade que o dinheiro possibilita torna-o um objeto universal, presente em todos os momentos da vida econômica cotidiana, representando parte significativa da vida social (MOREIRA, 2000). Assim, neste trabalho, busca-se entender o comportamento financeiro dos jovens que se mudaram para estudar em Santa Maria, RS. O estudo se caracteriza como uma pesquisa descritiva e quantitativa, tendo como amostra a população de jovens naturais de cidades distintas de Santa Maria que frequentam cursos de graduação, utilizando questionários baseados na Escala de Significado do Dinheiro, de Schwartz (1992), e adaptada por Moreira (2000). Foram obtidos 500 questionários, sendo utilizadas a Análise Fatorial e a Modelagem de Equações Estruturais na análise dos resultados. Os resultados estão relacionados aos 10 fatores da escala: conflito, poder positivo, progresso, prazer, cultura, poder negativo, desapego,
\end{abstract}

\footnotetext{
${ }^{1}$ Mestre em Administração pela Universidade Federal de Santa Maria (UFSM); Bacharela em Ciências Contábeis pelo Instituto Cenecista de Ensino Superior de Santo Ângelo (CNEC); escriturária no Banco do Estado do Rio Grande do Sul (Banrisul) desde dezembro de 2011. E-mail: claulunardis@ hotmail.com.

2 Doutor em Engenharia de Produção pela Universidade Federal de Santa Catarina (UFSC); Mestre em Engenharia de Produção pela Universidade Federal de Santa Maria (UFSM); Especialista em Estatística e Modelagem Quantitativa (UFSM); Licenciado em Matemática pela Faculdade Imaculada Conceição (FIC); Publicou 223 artigos em periódicos especializados e 572 trabalhos em anais de eventos. Possui 7 livros publicados e 30 capítulos de livros. Participou de 111 eventos. Orientou 3 teses de doutorado, 59 dissertações de mestrado, co-orientou 8, orientou 74 monografias de especialização, 49 trabalhos de iniciação científica e 52 trabalhos de conclusão de curso nas áreas de Administração, Engenharia de Produção, Estatística Aplicada e Enfermagem. Recebeu 20 prêmios e/ou homenagens. Membro do Comitê de Avaliadores do MEC, FAPEMA, FAPESPA e FAPESC. Membro do Comitê Científico da CAPES e CNPq na área de Administração. Tem experiência na área de: - Estatística: com ênfase em Métodos Quantitativos e Análise Multivariada; Administração, com ênfase em Inovação Tecnológica, Comportamento organizacional e Doenças Comportamentais. Em seu currículo Lattes os termos mais frequentes na contextualização da produção científica, tecnológica são: estatística aplicada, inovação tecnológica, comportamento organizacional e doenças comportamentais. Em suas atividades profissionais interagiu com 1585 colaboradores em co-autorias de projetos, grupos de pesquisa e trabalhos e artigos científicos. E-mail: 1flopes67@yahoo.com.

3 Mestranda em Administração pela Universidade Federal de Santa Maria (UFSM); Bacharela em Administração pela Universidade do Vale do Itajaí (UNIVALI); pesquisadora no Grupo de Pesquisa Comportamento, Estresse e Trabalho - GPCET/UFSM, sob a orientação do Prof. Dr. Luis Felipe Dias Lopes; Graduada em Administração pela Universidade do Vale do Itajaí (2012); possui experiência na área administrativa. E-mail: jucielecoradini@ hotmail.com.

${ }^{4}$ Doutorando em Administração pela Universidade Federal de Santa Maria (UFSM); Mestre em Administração (UFSM); Bacharel em Administração pela Faculdade Metodista Centenário (FMC); as áreas com interesse de pesquisa são Gestão de Pessoas e Gestão Pública, atuando principalmente nos seguintes temas: bem-estar no trabalho, satisfação no trabalho, qualidade de vida no trabalho, estresse ocupacional, síndrome de burnout, compra pública, licitação e contrato administrativo. E-mail: jonathan.saidelles@ gmail.com.

${ }^{5}$ Doutora em Administração pela Universidade Federal de Santa Maria (UFSM); Mestre em Administração (UFSM); Especialização em Gestão de Negócios pela Universidade Franciscana (UFN); Especialização em Educação Infantil (UFN); Bacharela em Administração pela Faculdade Metodista Centenário (FMC); Bacharela em Educação Especial (UFSM); As áreas com interesse de pesquisa são Gestão de Pessoas, Comportamento Organizacional e Saúde do Trabalhador. Possui experiência em atividades de liderança, trabalho em equipe, docência e grupos de pesquisa. E-mail: adm.damiana@gmail.com.
} 
sofrimento, generosidade e estabilidade. A maior média foi apresentada pelo fator 'estabilidade' $(3,84)$, enquanto a menor média foi relacionada ao fator 'sofrimento' $(2,68)$. Palavras-chave: dinheiro; jovens; Finanças Comportamentais; Administração; Psicologia.

Different ways to see the money: the perspective of young people study in Santa Maria.

\begin{abstract}
The convertibility that money makes possible makes it a universal object, present in all moments of everyday economic life, representing a significant part of social life (MOREIRA, 2000). Thus, in this work, we seek to understand the financial behavior of young people who moved to study in Santa Maria, RS. The study is characterized as a descriptive and quantitative research, having as a sample the population of young people from different cities in Santa Maria who attend undergraduate courses, using questionnaires based on Schwartz's Scale of Meaning of Money (1992) and adapted by Moreira (2000). 500 questionnaires were obtained, using Factor Analysis and Structural Equation Modeling to analyze the results. The results are related to the 10 factors of the scale: conflict, positive power, progress, pleasure, culture, negative power, detachment, suffering, generosity and stability. The highest mean was presented by the factor 'stability' (3.84), while the lowest mean was related to the factor 'suffering' (2.68).
\end{abstract}

Keywords: money; young; Behavioral Finance; Administration; Psychology.

Diferentes formas de ver el dinero: la perspectiva de los jóvenes que vienen a estudiar a Santa María

Resumen: La convertibilidad que permite el dinero lo convierte en un objeto universal, presente en todos los tiempos de la vida económica cotidiana, representando una parte significativa de la vida social (MOREIRA, 2000). Así, en este trabajo, buscamos entender el comportamiento financiero de los jóvenes que se mudaron a estudiar en Santa María, RS. El estudio se caracteriza por ser una investigación descriptiva y cuantitativa, teniendo como muestra la población de jóvenes de diferentes ciudades de Santa María que asisten a cursos de grado, utilizando cuestionarios basados en la Escala del Significado del Dinero, por Schwartz (1992), y adaptados por Moreira (2000). Se obtuvieron un total de 500 cuestionarios, utilizando Análisis de Factores y Modelado de Ecuaciones Estructurales en el análisis de los resultados. Los resultados están relacionados con los 10 factores de la escala: conflicto, poder positivo, progreso, placer, cultura, poder negativo, desapego, sufrimiento, generosidad y estabilidad. La media más alta fue presentada por el factor 'estabilidad' (3.84), mientras que la media más baja estaba relacionada con el factor 'sufrimiento' (2.68).

Palabras clave: dinero; jóvenes; Finanzas conductuales; Administración; Psicología.

\title{
1 Introdução
}

As Finanças Comportamentais vêm ganhando crescente reconhecimento no mundo acadêmico e fora dele. Seu traço distintivo é a incorporação de conceitos de outras áreas (como Psicologia e Sociologia) à Economia e à Administração para explicar as decisões financeiras dos indivíduos. Esse campo de estudo foi desenvolvido por dois psicólogos israelenses, Daniel Kahneman e Amos Tversky, em 1979, por meio de um trabalho intitulado "Teoria do Prospecto" (ARRUDA, 2006). As teorias tradicionais de Finanças foram construídas a partir de uma abordagem microeconômica neoclássica, cujo paradigma central é a racionalidade dos agentes econômicos. 
Porém, a validade das premissas assumidas por teorias vem sendo questionada. Uma de suas abordagens é o significado que as pessoas dão ao dinheiro, quais são as variáveis que as pessoas levam em consideração para chegar a esse significado. $\mathrm{O}$ dinheiro é um conceito estudado por diferentes áreas da ciência e está relacionado à vida cotidiana de todas as pessoas. A conversibilidade que o dinheiro possibilita faz dele um objeto concomitantemente universal, presente em todos os momentos da vida econômica cotidiana, constituindo parte significativa da vida social (MOREIRA, 2000). No entanto, o dinheiro, que deveria ter o papel de ser um intermediário de trocas, acaba assumindo diversos papéis, visto que as moedas refletem a mentalidade de um povo. Por meio dela podem ser observados aspectos políticos, econômicos, tecnológicos e culturais.

Segundo Carneiro, Franco e Barbieri (2016), o dinheiro passou a ser visto como um meio de pagamento mais seguro em uma sociedade. Os autores afirmam que a existência do dinheiro serve para amenizar os tipos de incertezas inerentes a um sistema de troca como era no escambo. Desse modo, observa-se o seu poder no cotidiano, ancorado às funções sociais, intervindo nas necessidades humanas individuais e sociais.

Para o autor Hayes (2018), o dinheiro possui valor variável em relação à renda, pois o nível de preço da produção sempre pode ser alterado. Pode-se dizer que o valor do meio de pagamento é o valor do preço da produção consumível, é a reserva de valor dominante pois seu valor em termos de produto consumível é o mais indiferente de tais mudanças no estado de expectativa de longo prazo.

Diante do exposto, algumas pesquisas surgiram para identificar o significado do dinheiro, buscando delimitar a estrutura cognitiva deste construto e variáveis a ele relacionadas (MOREIRA, 2000). Desse modo, o entendimento das relações entre os indivíduos e o dinheiro formam um campo de estudo emergente tanto na Psicologia como na Economia. Este trabalho tem por finalidade avaliar o significado do dinheiro para os jovens que se mudaram para estudar em uma instituição de Santa Maria - RS, sobre o controle de suas finanças pessoais, buscando entender esse comportamento financeiro. No que se refere à metodologia, é uma pesquisa de natureza descritiva com abordagem quantitativa em uma amostra com quinhentos respondentes.

Buscando orientar e expandir a discussão do presente estudo, apresenta-se nas seções seguintes o referencial teórico, bem como a definição de pesquisa das diferentes formas de ver o dinheiro. Por fim, apresentam-se a discussão dos resultados sobre os dados coletados e as considerações finais, assim como as sugestões para estudos futuros e limitações do presente estudo. 


\section{Fundamentação Teórica}

\subsection{Finanças Comportamentais e a Definição de Valores}

Segundo Oliveira e Montibeler (2017), a pesquisa na área de Finanças Comportamentais tem mostrado grande relevância no exterior, e aos poucos vem ganhando significativa expressão aqui no Brasil. Alguns eventos têm ganhado significativa importância, bons pesquisadores vêm se dedicando a estudar o tema, como exemplo na Conferência de Ciências Comportamentais e Educação do Investidor e no Encontro Brasileiro de Economia e Finanças Comportamentais.

A Finança Comportamental é justamente a identificação de como as emoções e os erros cognitivos podem influenciar no processo de decisão e como esses padrões de comportamento podem determinar mudanças no mercado. Essa ainda é uma área muito recente onde se tem muito que se estudar. Esse novo modelo surgiu há quase quarenta anos, por meio das pesquisas realizadas pelos psicólogos Amos Tversky e Daniel Kahneman (1974).

Os valores têm sido utilizados para explicar as mudanças que ocorrem na sociedade, o comportamento das pessoas, julgar ações, além de diferenciar nações e grupos. Os filósofos foram os primeiros a se preocupar com esta questão. Somente a partir do início do século $\mathrm{XX}$, os cientistas sociais se apropriaram do assunto e passaram a elaborar contribuições significativas para o tema (PORTO; TAMAYO, 2003).

A teoria de valores define dez tipos motivacionais conforme a motivação subjacente a cada um deles, presumindo-se que esses tipos motivacionais (conflito, poder positivo, poder negativo, progresso, prazer, cultura, sofrimento, desafio, generosidade e estabilidade) abranjam o conjunto de valores distintos reconhecidos entre as culturas. A elaboração de um modelo é progressiva e implica a necessidade de um trajeto contínuo de ida e volta entre a realidade e o modelo proposto (SCHWARTZ; BILSKY, 1987).

Os professores de mercadologia da Fundação Getulio Vargas (FGV) relacionam as necessidades culturais com o consumo. Segundo eles, depende da cultura de cada pessoa (por exemplo, preferir ler a ver televisão, ou música), havendo maior ou menor predisposição ao consumo e, consequentemente, mercado maior ou menor para determinados produtos e serviços (DIAS, 2003). 
Observa-se que por meio do tempo e do espaço, o dinheiro tem assumido diferentes formas, importância e significados. Ele pode ser definido como um instrumento de comércio e como medida de valor, tendo um impacto significante no comportamento das pessoas, no desempenho e efetividade nas organizações (SMITH, 1937).

As trocas efetivadas no mundo social no que diz respeito à sociedade moderna são marcadas fortemente pela presença do dinheiro para sua intermediação. Na percepção de Gudin (1965), observa-se que ninguém deseja a moeda por si, mas sim, pelo poder de compra que ela concede. Por outro lado, Moreira (2002) salienta que o conceito de dinheiro é determinado por sua função como meio de troca.

Weatherford (2005) evidencia que "o dinheiro é estritamente uma invenção humana por se tratar, em si mesmo, de uma metáfora - ele quer dizer outra coisa". Essa "outra coisa" que o dinheiro significa, ou seja, a sua metáfora, tem sido estudada, teorizada e discutida por várias áreas de conhecimento. Esse significado está diretamente relacionado com a percepção das pessoas sobre materialismo e seus comportamentos.

Rosa e Milani (2015) afirmam que o dinheiro pode interferir no comportamento das pessoas devido ao laço que o indivíduo possui com o dinheiro e a sociedade, trazendo a sensação de prazer, status, autonomia entre outros. Já sua falta, ou quantia insuficiente, pode acarretar os sentimentos de rejeição e exclusão do meio social. A moeda de troca se faz presente em várias áreas sociais, culturais, econômicas desde o poder até realização e sentimentos de sofrimento.

Diversos estudos já foram feitos a respeito da ligação dos estudantes com o dinheiro. Lynn, Yamauchi e Tachibana (1991) indicaram escores mais altos para estudantes japoneses que para estudantes ingleses em competitividade e valorização do dinheiro. Em um novo estudo, Furnham (1996) indicou que o dinheiro foi considerado mais importante nos países mais pobres, enquanto nos países mais ricos haveria menor preocupação em ganhar e poupar dinheiro.

Segundo Ferreira (2017), é possível fazer julgamentos inteligentes em relação ao dinheiro, transações financeiras e consumo, o que proporciona certo bem-estar e tranquilidade na vida. A educação financeira pode ser um meio básico e eficaz de, em um sistema econômico capitalista, se conquistar a qualidade de vida, por meio desses fatores.

O valor do dinheiro não se restringe apenas a um papel ou moeda de troca, mas vai além, atribuindo poder de compra e conquistas e carregando significados. Em qualquer lugar o dinheiro usado não será definido apenas por propriedades materiais, mas pelas qualidades simbólicas, vinculadas aos ideais de poder (CARNEIRO; FRANCO; BARBIERI, 2016). 
Dadas essas definições e singularidades referentes às Finanças Comportamentais, no Tópico 3 está detalhado o método utilizado como base para a análise do estudo.

\section{Método}

O presente estudo se caracteriza como uma pesquisa descritiva. Marconi e Lakatos (2010) afirmam que na pesquisa descritiva, os fatos são observados, registrados, analisados, classificados e interpretados, sem que o pesquisador interfira neles. De acordo com Vergara (2000), a pesquisa descritiva estabelece as relações entre variáveis, isto é, aquelas que visam a estudar as características de um grupo: sua distribuição por idade, sexo, procedência, nível de escolaridade, estado de saúde física e mental e outros.

Quanto à abordagem, classifica-se como uma pesquisa quantitativa, pois segundo Fachin (2006), a variável quantitativa é determinada em relação aos dados ou à proporção numérica, mas a atribuição numérica não pode ser feita ao acaso, porque a variação de uma propriedade não é quantificada cientificamente. A amostra estudada foi selecionada por conveniência dentro da população de jovens graduandos que frequentam cursos de graduação da Universidade Federal de Santa Maria (UFSM) das mais diversas áreas.

Hair et al. (2005) afirmam como regra geral que deve-se ter pelo menos cinco vezes mais observações do que o número de variáveis a serem analisadas. Assim, considerando que o instrumento foi composto por oitenta e duas afirmativas, a amostra deveria ser composta por no mínimo quatrocentos e dez respondentes. Finalizada a coleta de dados, alcançou-se quinhentos participantes, sendo que somente um questionário não foi considerado válido, sendo retirado da amostra.

Referente ao questionário, foi dividido em duas partes: a primeira buscou identificar aspecto de perfil da população investigada, tal como idade, gênero, escolaridade, estado civil e, também, perguntas demográficas para caracterizar os entrevistados. Como base para isso, foi tomado o questionário utilizado pela UFSM em seu vestibular.

A segunda parte foi composta por questões relativas ao tema pesquisado, extraídas da Escala de Significado do Dinheiro de Schwartz (1992), adaptada por Moreira (2000). O questionário original proposto por Moreira (2000) continha duzentas questões; durante a análise, somente oitenta e duas frases foram consideradas significativas pela autora. Da mesma forma que Moreira (2000) utilizou em sua tese de doutorado, essas frases foram acompanhadas de uma escala tipo Likert de cinco pontos (discordo totalmente - concordo totalmente). 
Para a análise dos dados foi utilizado o software Statistical Package for the Social Sciences (SPSS) versão 18.0, visando à mensuração, à organização e ao cruzamento das variáveis levantadas. Também foi utilizado o programa AMOS, um software de modelização de equações estruturais (SEM), o qual permite suportar a sua investigação e os estudos efetuados através da extensão dos métodos mais comuns de análise multivariada, incluindo a análise fatorial.

\section{Discussões e Resultados}

Primeiramente, no que tange à amostra, pode-se observar que a distribuição dos alunos (sexo, origem, estado civil, filhos e moradia) se deu da seguinte forma: $52,71 \%$ dos respondentes são do sexo feminino, 92,38\% são originários do Estado do Rio Grande do Sul, 96,59\% são solteiros, 1,20\% têm filhos e 42,28\% pagam aluguel. Em relação aos dados referentes com quem residiam e o tipo de instituição onde cursaram o Ensino Médio, obtevese que 58,32\% moravam com amigos, seguidos por aqueles que moram: com irmãos $(11,02 \%)$, sozinhos $(10,02 \%)$ e com os pais $(3,81 \%)$. No que diz respeito à escola em que cursaram o Ensino Médio, 68,54\% afirmaram terem cursado em escolas públicas, já 22,04\% cursaram em escolas particulares e $0,20 \%$ via supletivo.

Sobre a graduação, contando com 60 cursos diferentes, observou-se que o curso de Engenharia Civil representou o maior percentual (10,82\%), seguido pelos cursos de Educação Física (9,82\%), Agronomia (8,82\%) e Administração (7,21\%). A maioria dos respondentes estava matriculado até o $6^{\circ}$ semestre, representando 79,56\%.

Segundo os dados obtidos, para 65,50\% dos participantes a escolha do curso de graduação decorre da adequação deste a suas aptidões e interesses; já para 7,82\% é devido à facilidade de mercado de trabalho, sendo que somente 5,21\% afirmaram ter escolhido pelo lado financeiro. Para a renda familiar, os resultados mostraram que 52,30\% dos respondentes se enquadram em uma faixa de até 4 salários mínimos e somente 5,01\% tem renda familiar acima de 17 salários mínimos.

No que se refere aos gastos, $47,90 \%$ dos alunos asseguram que gastam o mesmo que ganham, ao passo que apenas $16,83 \%$ gastam mais do que o que recebem como renda. No entanto, quando questionados sobre poupar, apenas 9,02\% afirmam poupar dinheiro sempre, já $34,67 \%$ poupam frequentemente e $32,67 \%$ poupam somente algumas vezes. A opção nunca poupar foi marcada por apenas $6,01 \%$. 
Em relação à interação com o dinheiro anterior à vinda dos alunos para Santa Maria, $39,68 \%$ asseguram que já possuíam responsabilidades em pagar contas e controlar seu dinheiro, já 29,06\% não possuíam preocupações relacionadas com o dinheiro. Para 26,65\% o recurso advém de mesada, os quais controlam esse valor para seus gastos pessoais. Em contraponto, somente $4,61 \%$ recebem mesada e acabam precisando de mais dinheiro posteriormente.

Para compreensão do significado do dinheiro para os jovens que vêm até Santa Maria para morar, foi realizada a análise fatorial com base nas respostas das oitenta e duas questões propostas pela Escala do Significado do Dinheiro. Para tanto foi adotada a análise de componentes principais como método de extração dos fatores. Com relação ao método de rotação, a opção adotada foi a rotação Varimax normalizada. Para o critério de extração foi estabelecido o autovalor maior que 1 e como condição para que a variável fosse mantida na análise, sua comunalidade necessitava ser superior a 0,4 (HAIR Jr. et al., 2005).

Para uma melhor compreensão da análise fatorial, optou-se por fixar a quantia de fatores artificialmente. Inicialmente foi testada a análise com oito fatores fixados; pela exclusão das comunalidades inferiores a 0,4 restaram somente trinta e duas variáveis para serem analisadas. Devido ao alto nível da exclusão, optou-se por não continuar a análise com tal quantia de valores. Num segundo momento, testou-se a fixação dos fatores em dez, obteve-se como resultado uma explicação de 52,008\%.

Excluídas as variáveis e mantidos os dez fatores artificialmente, a nova análise fatorial apresentou índice de 0,813 no teste KMO e a especificidade de Bartlett assumiu desta vez o valor de 6631,778 significativos a $1 \%$.

\begin{tabular}{l|c|c|c|c|c}
\hline \multicolumn{1}{c|}{ Questões } & \multicolumn{3}{c}{ Fatores } & $\mathbf{5}$ \\
\cline { 2 - 6 } & $\mathbf{1}$ & $\mathbf{2}$ & $\mathbf{3}$ & $\mathbf{4}$ & $\mathbf{5}$ \\
\hline 34- Dinheiro gera desarmonia nas famílias & 0,670 & & & & \\
37- Dinheiro provoca desavenças com parentes & 0,699 & & & & \\
38- Dinheiro gera ingratidão & 0,641 & & & & \\
43- Dinheiro é sinônimo de dor de cabeça & 0,555 & & & & \\
48- Dinheiro provoca descontrole emocional & 0,670 & & & & \\
55- Dinheiro provoca traições & 0,564 & & & & \\
65- Dinheiro provoca frustrações & 0,669 & & & & \\
68- O dinheiro provoca jogos de interesse & 0,521 & & & & \\
79- Dinheiro provoca ilusões & 0,590 & & & & \\
81- Dinheiro provoca neuroses & 0,631 & & & & \\
\hline 04- Quem tem dinheiro tem autoridade sobre os outros & & 0,589 & & & \\
06- Dinheiro possibilita ascensão social & & 0,593 & & & \\
09- Dinheiro traz reconhecimento social & & 0,664 & & & \\
23- Dinheiro é sinônimo de dominação & & 0,561 & & &
\end{tabular}


52- Quem tem dinheiro é valorizado socialmente

59- Ter dinheiro é ter poder

69- Dinheiro significa status social

74- É preciso ter dinheiro para ter prestígio

08- O dinheiro constrói um mundo melhor

18- O dinheiro ajuda a evolução da humanidade

46- Dinheiro garante prosperidade para a sociedade

57- Dinheiro traz esperança no futuro

58- O dinheiro facilita a vida da humanidade

11- Dinheiro significa prazer

16- O dinheiro ajuda a tornar as relações amorosas mais agradáveis

44- Dinheiro atrai felicidade

47- O dinheiro facilita a convivência familiar

82- Dinheiro ajuda a ter harmonia familiar

12- Com dinheiro eu patrocinaria o desenvolvimento das artes

35- Com dinheiro eu investiria em pesquisas científicas

56- Quem tem dinheiro deve empregá-lo no

desenvolvimento do país

63- Eu investiria dinheiro em eventos culturais

78- Eu investiria dinheiro em inovações tecnológicas

\begin{tabular}{|c|c|c|c|}
\hline $\begin{array}{l}0,547 \\
0,683 \\
0,679 \\
0,406\end{array}$ & & & \\
\hline & $\begin{array}{l}0,678 \\
0,676 \\
0,715 \\
0,660 \\
0,658\end{array}$ & & \\
\hline & & $\begin{array}{r}0,493 \\
0,551 \\
0,536 \\
0,776 \\
0,762\end{array}$ & \\
\hline & & & $\begin{array}{l}0,577 \\
0,724 \\
0,512 \\
0,697 \\
0,691 \\
\end{array}$ \\
\hline
\end{tabular}

\begin{tabular}{|c|c|c|c|c|c|}
\hline \multirow{2}{*}{ Questões } & \multicolumn{5}{|c|}{ Fatores } \\
\hline & 6 & 7 & 8 & 9 & 10 \\
\hline $\begin{array}{l}\text { 26- Crianças ricas são ensinadas a evitar contato com } \\
\text { crianças pobres } \\
\text { 31- Quem tem dinheiro é o primeiro a ser atendido em } \\
\text { todos os lugares } \\
\text { 40- As pessoas submetem-se a quem tem dinheiro } \\
\text { 66- Quem tem dinheiro passa por cima das normas } \\
\text { estabelecidas } \\
\text { 77- Crianças ricas são educadas para mandar }\end{array}$ & $\begin{array}{l}0,636 \\
6,770 \\
0,466 \\
0,522 \\
0,609\end{array}$ & & & & \\
\hline $\begin{array}{l}\text { 05- Quem tem fé sabe que precisa fazer caridade } \\
\text { 29- Recompensas espirituais são mais importantes que } \\
\text { dinheiro } \\
\text { 60- É dever de todas as pessoas dividirem o que têm } \\
\text { 67- Basta crer em Deus para ter as necessidades } \\
\text { atendidas }\end{array}$ & & $\begin{array}{l}0,681 \\
0,467 \\
0,469 \\
0,667\end{array}$ & & & \\
\hline $\begin{array}{l}\text { 24- Dinheiro é uma coisa complicada para mim } \\
\text { 32- Pensar em dinheiro me deixa deprimido }\end{array}$ & & & $\begin{array}{l}0,663 \\
0,673\end{array}$ & & \\
\hline $\begin{array}{l}\text { 49- Ajudar quem precisa é melhor que guardar dinheiro } \\
\text { 50- Os pais devem ensinar os filhos a serem generosos }\end{array}$ & & & & $\begin{array}{l}0,683 \\
0,776\end{array}$ & \\
\hline $\begin{array}{l}\text { 13- Acho importante ter seguro de vida } \\
\text { 54- Acho importante fazer convênios de saúde }\end{array}$ & & & & & $\begin{array}{l}0,727 \\
0,756\end{array}$ \\
\hline
\end{tabular}

Tabela 1: Variáveis relacionadas aos fatores. Fonte: elaborado pelos pesquisadores. 
De acordo com a análise da matriz rotacionada pelo método Varimax, para melhor visualização dos fatores e da significância de cada variável dentro dos mesmos foram nomeados cada um dos fatores. O primeiro fator, composto por dez variáveis, foi nominado de Conflito, demonstrando que o sofrimento é algo intimamente ligado ao dinheiro. Já o segundo fator, denominado Poder Positivo, trouxe uma visão, como o nome mesmo já representa, positiva sobre o dinheiro, sendo composto por oito variáveis. Mostra-se aqui um contraponto, já que os dois fatores mais relevantes estão ligados a sentimentos opostos sobre o dinheiro.

O terceiro fator, composto por cinco variáveis, recebeu como nome Progresso, por trazer questões ligadas ao desenvolvimento da sociedade, sendo esse mais um fator positivo ligado ao dinheiro, já que trata dos benefícios obtidos coletivamente pelo dinheiro. O quarto fator foi obtido em uma soma de cinco questões relacionadas à visão positiva do dinheiro, sendo assim foi denominado Prazer. Nesse fator apresentam-se questões sobre os benefícios trazidos pelo dinheiro referentes à convivência familiar, amorosa e a felicidade por ele trazida.

O quinto fator foi nomeado como Cultura, já que este apresenta cinco questões que abordam sobre os investimentos em pesquisas científicas, desenvolvimento das artes e cultura propriamente dita. $\mathrm{O}$ fator de número seis foi chamado de Poder Negativo, por trazer uma visão ruim a respeito do dinheiro; usado como forma de manipulação das pessoas e das normas, este fator traz especialmente uma imagem fortemente negativa que as pessoas associam ao dinheiro. Este fator foi formado por cinco questões.

Os sétimo e oitavo fatores foram nomeados, respectivamente, de Desapego, contendo quatro questões, e de Sofrimento, contendo duas questões. O fator Desapego trouxe questões relacionadas à espiritualidade, enquanto o fator Sofrimento traz uma exposição clara das amarguras trazidas pelo dinheiro. O nono fator, Generosidade, traz duas questões sobre ajudar o próximo doando dinheiro. Por fim, o décimo fator é o resultado de duas questões que abordam as seguranças trazidas pelo dinheiro, e por este motivo recebeu o nome de Estabilidade.

A modelagem de equações estruturais (MEE), segundo Hair et al. (2005), possibilita ao pesquisador estimar a magnitude dos efeitos estabelecidos entre as variáveis e testar se o modelo utilizado é consistente com os dados observados. Sendo assim, para a validação individual dos construtos foi realizada a Análise Fatorial Confirmatória (AFC), de modo que os testes gerados foram objetivando verificar os pressupostos básicos da modelagem de equações estruturais: normalidade, linearidade e homoscedasticidade. Os resultados obtidos 
em relação aos índices de ajuste do modelo e confiabilidade podem ser visualizados na Tabela 2.

Após a realização das análises sobre os pressupostos para a modelagem de equações estruturais (MEE), procedeu-se o teste do modelo. Segundo Hair et al. (2005), a MEE possibilita ao pesquisador estimar a magnitude dos efeitos estabelecidos entre as variáveis e testar se o modelo utilizado é consistente com os dados observados.

\begin{tabular}{|c|c|r|r|}
\hline Tipo & Índices & Inicial & \multicolumn{1}{|c|}{ Final } \\
\hline \multirow{4}{*}{ Medidas de Ajuste Absoluto } & CMIM & 2216,773 & 750,401 \\
\cline { 2 - 4 } & DF & 1037 & 478 \\
\cline { 2 - 4 } & CMIM/DF & 2,138 & 1,57 \\
\cline { 2 - 4 } & GFI & 0,835 & 0,918 \\
\cline { 2 - 4 } & AGFI & 0,813 & 0,897 \\
\hline \multirow{3}{*}{ Medidas de Ajuste Comparativo } & CFI & 0,794 & 0,92 \\
\cline { 2 - 4 } & NFI & 0,677 & 0,811 \\
\cline { 2 - 4 } & TLI & 0,776 & 0,906 \\
\hline Medida de Ajuste Parcimonioso & RMSEA & 0,048 & 0,034 \\
\hline
\end{tabular}

Tabela 2: Medidas de ajuste das Equações Estruturais. Fonte: elaborado pela pesquisadora.

Analisando os resultados obtidos, verifica-se que o modelo tem um bom nível de ajuste, em virtude de que o índice de qualidade do ajuste (GFI), índice ajustado de qualidade do ajuste (AGFI) e qui-quadrado apresentaram resultados dentro dos limites adequados. $\mathrm{O}$ construto analisado foi formado por dez variáveis (fatores). Após o cálculo de todos os índices de ajuste considerados para o modelo, verificou-se que o teste qui-quadrado é significativo $(\mathrm{p}=0,0001)$, a raiz do erro quadrático médio de aproximação (RMSEA) apresenta-se inferior a 0,08. Algumas medidas de ajuste também apresentaram valores fora dos limites aceitáveis: índice de ajuste ponderado (NFI) é inferior a 0,9.

Empregou-se a estratégia de aprimoramento do modelo. Hair Jr et al. (2005) propõem quatro ações corretivas para resolver problemas de identificação do modelo. As ações devem ser executadas na seguinte ordem: (1) construir um modelo com um número mínimo de coeficientes; (2) caso seja possível, fixar as variâncias de erros de mensuração; (3) fixar os coeficientes de estruturais conhecidos; e (4) eliminar variáveis problemáticas. Foi adotada neste caso a eliminação das variáveis problemáticas.

Conforme demonstrado acima, a variável 1 (Fator Conflito) permaneceu com cinco questões e seus erros formando seu constructo; as demais questões, por não atenderem às exigências, foram descartadas do modelo. A variável 2 (Fator Poder Positivo) permaneceu com quatro questões e seus erros; já a variável 3 (Fator Progresso) e a variável 4 (Fator 
Prazer) não tiveram questões retiradas, permanecendo com todo seu constructo válido. A variável 5 (Fator Cultura) teve somente duas questões retiradas, ou seja, permaneceram três questões e seus erros, enquanto a variável 6 (Fator Poder Negativo) (...). Por fim, a variável 7 (Fator Desapego) e as demais variáveis, variável 8 (Fator Sofrimento), variável 9 (Fator Generosidade) e variável 10 (Fator Estabilidade), mantiveram duas questões. Fica visível uma interação de todos os fatores, ou seja, cada um dos fatores obteve uma comunalidade com os outros nove fatores.

\section{Considerações Finais}

Este artigo apresenta inicialmente um breve histórico sobre Finanças Comportamentais nas instituições e modos de vida, ao mesmo tempo em que substituiu sistemas anteriores. Nesse sentido, o estudo contextualiza e detalha a investigação sobre qual o significado do dinheiro para o jovem estudante universitário da UFSM, no controle de suas finanças. Por meio dos resultados, percebe-se a importância da pesquisa, podendo colaborar para o conhecimento de novos comportamentos com outras linhas de estudo.

Observou-se através da coleta de dados que estes mostraram-se adequados para a aplicação da técnica de Análise Fatorial. A análise identificou um total de dez fatores fixados artificialmente, esses fatores foram nomeados tais como: conflito, poder positivo, progresso, prazer, cultura, poder negativo, desapego, sofrimento, generosidade e estabilidade. Percebese que os alunos demonstraram uma preocupação já latente com relação ao dinheiro, ao mesmo tempo em que poucos afirmaram já ter a preocupação em poupar, pensando no futuro ou mesmo em minimizar gastos para os pais.

De acordo com os resultados, ainda, o fator Conflito foi responsável por explicar $12,65 \%$ da variância, já o fator Poder Positivo conseguiu explicar 9,13\% da variância. Os fatores Progresso e Prazer, por sua vez, explicaram, respectivamente, 6,04\% e 5,32\%. No total, os dez fatores juntos explicaram $52 \%$ da variância. Percebe-se que o dinheiro possui significados que vão muito além de sua função principal, que seria um meio de troca, ou seja, que existe a influência de outros fatores como cultura, classe social, escolaridade e diversas outras características inerentes a cada grupo de indivíduos.

Como limitação do estudo, destaca-se o corte transversal e a impossibilidade de estratificar a amostra no intuito de realizar comparações entre os alunos de cada curso. Para trabalhos futuros, sugere-se a realização de um estudo que analise o significado do valor do dinheiro comparando cursos universitários, classes sociais e faixas etárias dos entrevistados. 
Além disso, entendemos ser relevante a realização desta mesma pesquisa não somente por meio de abordagem quantitativa, mas também qualitativa, realizando entrevistas com alunos para maiores detalhes sobre este comportamento.

\section{Referências}

ARRUDA, P. B. Uma investigação sobre o efeito disposição. 2006. Dissertação (Mestrado em Engenharia de Produção - Universidade Federal de Santa Catarina, Florianópolis, 2006.

CARNEIRO, A. R. V.; FRANCO; BARBIÉRI, E. S. F. Representações sociais de estudantes universitários sobre dinheiro. Psicologia da Educação, PUCSP, São Paulo, n.43, 2016. Disponível em: https://revistas.pucsp.br/psicoeduca/article/view/34432.

DIAS, M. M. Moda e mercado do olhar. In: ZILIOTTO, D. M. (org). O consumidor: objeto da cultura. Petrópolis, Vozes, 2003.

FACHIN, O. Fundamentos de metodologia. 5. ed. São Paulo, Saraiva, 2006.

FERREIRA, J. C. A importância da educação financeira pessoal para a qualidade de vida. Caderno de Administração v.1 Ano 2017.

FURNHAM, A. Attitudinal correlates and demographic predictors of monetary beliefs and behaviours. Journal of Organisational Behavior, 17(4), p. 375-388, 1996.

GUDIN, E. Princípios de economia monetária. 5. ed. Rio de Janeiro: Agir, 1965.

HAIR, Jr. J. F.; ANDERSON, R. E.; TATHAM, R. L.; BLACK, W. Fundamentos de Métodos de Pesquisa em Administração. Porto Alegre: Bookman, 2005.

HAYES, M. G. The liquidity of money. Cambridge Journal of Economics, 2018.

LYNN, R., YAMAUCHI, H.; TACHIBANA, Y. Attitudes related to work of adolescents in the United Kingdom and Japan. Psychological Reports, 68(2), p. 403-410, 1991.

MARCONI, M. A.; LAKATOS, E. M. Fundamentos de metodologia científica. 7. ed. São Paulo: Atlas, 2010.

MOREIRA, A. S. Valores e dinheiros: um estudo transcultural da relação entre prioridades de valores e significado do dinheiro para indivíduos. Tese de doutorado não-publicada, Universidade de Brasília, Brasília, 2000.

MOREIRA, A. S. Dinheiro no Brasil: Um estudo comparativo do significado do dinheiro entre as regiões geográficas brasileiras. Revista Estudos de Psicologia, v.7, n.2, 2002.

OLIVEIRA, J. N.; MONTIBELER, E. E. Finanças comportamentais: um estudo sobre a aversão a perda na tomada de decisão. Revista Eletrônica Estácio Papirus, v.4, n.2, p. 147$162,2017$. 
PORTO, J. B.; TAMAYO, A. Escala de Valores Relativos ao Trabalho - EVT. Psicologia: Teoria e Pesquisa. Brasília, v. 19, p. 145-152, 2003.

ROSA I. R; MILANI, B. Significado do Dinheiro: Um Estudo Sobre o Comportamento de Estudantes de Nível Superior. RAIMED - Revista de Administração IMED, 2015.

SCHWARTZ, S. H. Universals in the content and structure of human values: theoretical advances and empirical tests in 20 countries. Advances in experimental social psychology. Orlando, F.L. Academic, v. 25, p. 1-65, 1992.

SCHWARTZ, S. H.; BILSKY, W. Toward a Universal Psychological Structure of human values. Journal of Personality and Social Psychology, n. 53, p. 550-562, 1987.

SMITH, A. An Inquiry into the Nature and Causes of the Wealth of Nations. New York, NY: Modern Library, 1937.

TVERSKY, A.; KAHNEMAN, D. Judgment under Uncertainty: Heuristics and Biases. Science, 1974.

TVERSKY, A.; KAHNEMAN, D. Prospect theory: an analysis of decision under risk. Econometrica, New York, v. 4, n. 2, p. 263-291, 1979.

VERGARA, S. C. Projetos e relatórios de pesquisa em administração. 3. ed. São Paulo, Atlas, 2000.

WEATHERFORD, J. M. A história do dinheiro. Rio de Janeiro: Elsevier, 2005. 